\title{
Echocardiographic comparison of haemodynamic effects of metoprolol and propranolol
}

\author{
J H N BETT, L DRYBURGH, D E HETHERINGTON \\ From Royal Brisbane Hospital, Brisbane, Australia
}

SUMMARY Metoprolol (200 mg daily) and propranolol (160 mg daily) were each given for one week to 11 normal subjects. The order of administration was randomised and not known to us during the study. Each period of treatment with active drug was followed by one week during which placebo tablets were taken.

M-mode echocardiograms and blood pressure were recorded before entry to the trial, twice during each week of treatment with metoprolol or propranolol, and daily for three days and on the seventh day after stopping the drugs. Septal and posterior wall endocardial echoes were traced with an X-Y digitiser and left ventricular minor axis dimensions derived every $10 \mathrm{~ms}$ with a minicomputer.

Both drugs reduced heart rate, cardiac output, and blood pressure. Systemic vascular resistance was increased significantly by propranolol, and with both agents was inversely related to heart rate, cardiac output, left ventricular diastolic dimension, and indices of contractility.

Beta-adrenergic blocking agents have measurable effects on haemodynamic, angiocardiographic, and echocardiographic indices of left ventricular function. We have used echocardiography to make repeated measurements of left ventricular dimensions and contractility and of cardiac output and systemic vascular resistance during a crossover trial of metoprolol and propranolol, and compared the effects of these agents and their duration after stopping each drug.

\section{Methods}

The subjects were normal volunteers who gave their informed consent. They were between 21 and 29 years of age, and were selected because we were able to record left ventricular echocardiograms of high quality. After baseline studies each subject took either propranolol ( $80 \mathrm{mg}$ bd orally) or metoprolol (100 mg bd orally) for one week (weeks 1 and 3). The order of administration was randomised and matching placebo was used throughout. During weeks 2 and 4 placebo only was given. The drugs were packaged in Dosetts, a weekly tablet dispensing system. The procedure is summarised in Fig. 1.

Echocardiograms were recorded before admission to the trial, twice during each phase of active Received for publication 8 March 1979 drug administration, and daily for three days and on the seventh day after the drugs were stopped. Blood pressure was recorded by sphygmomanometry at each visit and a blood sample was taken for estimation of plasma level of active drug ${ }^{1}$ at the end of the first and third weeks.

Standard left ventricular echocardiograms were recorded with the subjects lying supine or rolled towards the left, using an Ekoline 20 A echocardio-

Echo BP
\begin{tabular}{|l|c|c|c|c|c|}
\hline Metoprolol & Placebo & Propranolol & \multicolumn{2}{c|}{ Placebo } \\
\hline $\begin{array}{l}\text { Days } \\
\text { Echo BP }\end{array}$ & 78910 & 14 & 3 & 78910 & 14 \\
\end{tabular}

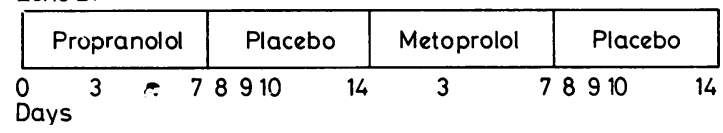

Fig. 1 Study procedure. Each subject was studied for four weeks. Active drugs were taken during the first and third weeks. Recordings of left ventricular dimensions (echo) and blood pressure (BP) were made at the beginning of the study (day 0), twice during each period of beta-adrenergic blockade (days 3, 7), daily for the first three days of each placebo phase (days $8,9,10$ ), and on day 14. Blood samples were taken for plasma levels of metoprolol and propranolol on day 7 of the first and third weeks. 
graph, Electronics for Medicine VR6 recorder, and 2.25 or $3.5 \mathrm{MHz}$ focused transducers, at a paper speed of $50 \mathrm{~mm} / \mathrm{s}$. Depth calibrations were checked against a standard test object, and time markers against a $50 \mathrm{~Hz}$ mains signal.

When the records were of sufficiently good quality the left ventricular septal and posterior wall endocardial echoes were traced with the cursor of an X-Y digitiser (Hewlett-Packard 9864A) through at least five cycles. Depth calibrations during the portion of the recording to be digitised, time markers (1 s), and onset of QRS were entered. Corrections were made for alignment of the recording on the digitising table, and for nonlinearity of the $1 \mathrm{~cm}$ depth calibrations. The data were analysed with a Hewlett Packard 9825A minicomputer with 23228 bytes of internal memory. Linear interpolation was used to derive ventricular dimensions at $10 \mathrm{~ms}$ intervals. A five-point running filter was used to reduce sampling jitter.

Dd (dimension at onset of QRS) and Ds (dimension at peak posterior wall excursion) were calculated and stored. The instantaneous gradients of ventricular dimension $(\mathrm{dD} / \mathrm{dt})$ were calculated and 'normalised' for the average minor axis diameter $([\mathrm{Dd}+\mathrm{Ds}] / 2)$. The gradient at a particular time was taken as the average of that during three preceding and following $10 \mathrm{~ms}$ intervals. The maximum systolic and diastolic gradients were stored (Fig. 2). When six or more cycles were digitised the computer calculated the mean and SD for each variable and rejected the value with the largest deviation. This was repeated until only five cycles were left. When the septal and posterior wall endocardium were not defined completely Dd, Ds, and $R-R$ interval were measured for five cycles.

Stroke volume (SV) and cardiac output ( $\left.\dot{Q}_{s}\right)$ were derived using cubed systolic and diastolic dimensions (eg $S V=[D d]^{3}-[D s]^{3}$ ) and using the formula of Teichholz et al. ${ }^{2}$ Systemic resistance $\left(R_{s}\right)$ was calculated assuming $\mathbf{B P}_{\text {mean }}=\left(\mathbf{B P}_{\left[d_{]}\right.}+\right.$ $\left[\mathrm{BP}_{[\mathrm{s}]}-\left[\mathrm{BP}_{[\mathrm{d}]}\right] / 3\right) \mathrm{mmHg}$ and right atrial mean pressure $0 \mathrm{mmHg}$.

Fractional shortening (FS) was derived from the formula $\mathrm{FS}=([\mathrm{Dd}-\mathrm{Ds}] / \mathrm{Dd}) \times 100$, and mean velocity of circumferential shortening (Vcf) from $\mathrm{Vcf}=[\mathrm{Dd}-\mathrm{Ds}] /[\mathrm{Dd} \times \mathrm{ET}]$ where ejection time (ET) was the interval from onset of QRS to peak posterior wall excursion-50 ms.

Statistical comparisons were made using Wilcoxon's signed rank test and Student's paired t test.

\section{Results}

Eleven subjects (six men, five women) were studied. None withdrew because of adverse reactions to either drug, and the only effect noted was undue fatigue during extremes of exertion such as playing squash. Mean values for the data are summarised in the Table. Baseline values (day 0 ) and those on days 14 and 28 did not differ significantly from those recorded on other normal adults in the same age range (men: Dd $50 \pm 3 \mathrm{~mm}$, Ds $34 \pm 4 \mathrm{~mm}$, systolic $\mathrm{dD} / \mathrm{dt}_{\max } 2 \cdot 2 \pm 0.4 \mathrm{diam} / \mathrm{s}$, diastolic $\mathrm{dD} /$ $\mathrm{dt}_{\max } 2 \cdot 3 \pm 0.6 \mathrm{diam} / \mathrm{s}$; women: $\mathrm{dD} 43 \pm 3 \mathrm{~mm}$, Ds $28 \pm 3 \mathrm{~mm}$, systolic $\mathrm{dD} / \mathrm{dt}_{\max } 2.5 \pm 0.4 \mathrm{diam} / \mathrm{s}$, diastolic $\mathrm{dD} / \mathrm{dt}_{\max } 3 \cdot 2 \pm 0 \cdot 7 \mathrm{diam} / \mathrm{s}$.

Both drugs produced significant reductions in heart rate, mean blood pressure, and cardiac output. With propranolol the heart rate and blood pressure reductions were still significant the day after the drug was stopped. Propranolol administration resulted in reduction in left ventricular diastolic dimension and diastolic $\mathrm{dD} / \mathrm{dt}_{\mathrm{max}}$, and with an increase in the systemic vascular resistance (Table). When the drugs were compared, mean values for diastolic dimension and cardiac output were greater with metoprolol, while diastolic $\mathrm{dD} / \mathrm{dt}_{\mathrm{max}}$, mean blood pressure, and peripheral resistance were less.

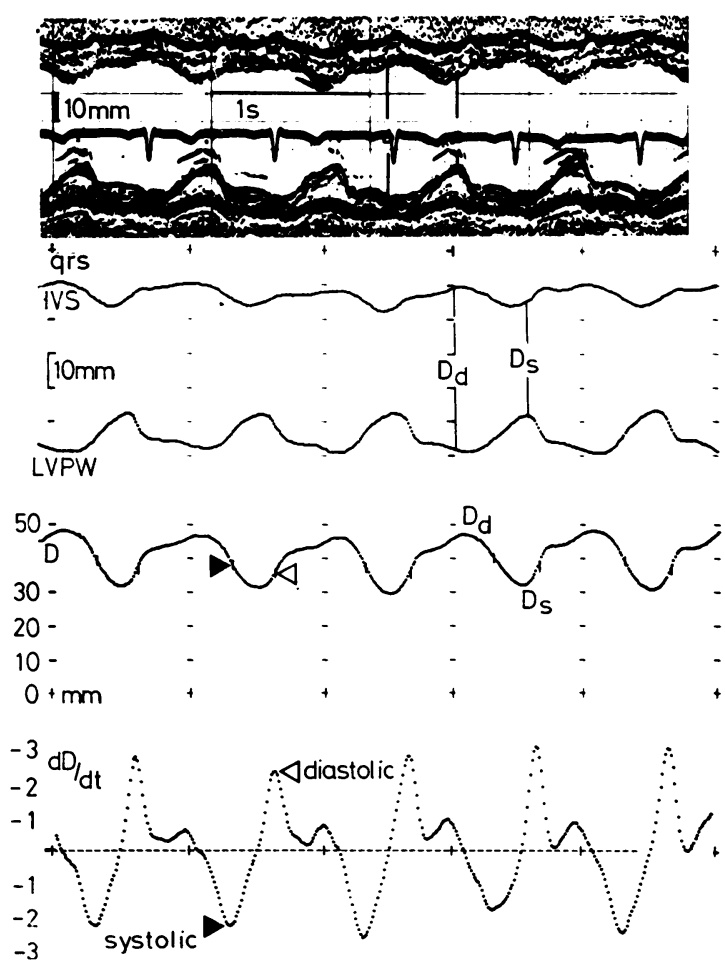

Fig. 2 Analysis of echocardiograms. A standard M-mode left ventricular echocardiogram is shown, with plots of septal (IVS) and posterior wall (LVPW) endocardium, instantaneous dimension (D), and "normalised" rate of change of dimension $(d D / d t)$. 
For both drugs there were significant negative correlations between peripheral vascular resistance and diastolic dimension $(r=0.67, p<0.001)$, mean Vcf $(r=0.42, p<0.05$ [propranolol]; $r=0.53$, $p<0.01$ [metoprolol]), fractional shortening $(r=0.59$ [propranolol] and 0.49 [metoprolol], $\mathrm{p}<0.001)$, systolic ( $r=0.48, p<0.001$ [propranolol], $r=0.32$, $\mathrm{p}<0.01$ [metoprolol]) and diastolic $(\mathrm{r}=0.41$ [propranolol[ and 0.42 [metoprolol], $\mathrm{p}<0.001) \mathrm{dD} /$ $\mathrm{dt}_{\max }$, heart rate $(\mathrm{r}=0.35, \mathrm{p}<0.01$ [propranolol], $r=0.42, p<0.001$ [metoprolol]), and cardiac output $(\mathrm{r}=0.87, \mathrm{p}<0.001)$.

Plasma levels of metoprolol $(0 \cdot 76 \pm 0 \cdot 46$, range 0.37 to $1.72 \mu \mathrm{mol} / \mathrm{l})$ and propranolol $(0.26 \pm 0.22$, range 0.03 to $0.66 \mu \mathrm{mol} / \mathrm{l}$ ) on day 7 of the administion of the active drug could not be correlated with changes from baseline values in heart rate, left ventricular dimensions, fractional shortening, blood pressure, cardiac output, or peripheral vascular resistance.

\section{Discussion}

Standardised echocardiographic methods ${ }^{3}$ have been used to determine left ventricular function in patients with heart disease ${ }^{45}$ and in subjects undergoing physical training, ${ }^{6}$ and during the administration of drugs. ${ }^{7-9}$ Comparisons with angiocardiography have confirmed the validity of the echocardiographic measurement of left ventricular dimensions and volumes, ${ }^{10-12}$ and of mean ${ }^{13} 14$ and peak ${ }^{15}$ rates of change of dimension. The expression of left ventricular volumes as cubed minor axis dimensions ${ }^{11}$ has been shown to be inaccurate in patients with ventricular dilatation or dyskinesia. ${ }^{2}$ We calculated volumes by cubing dimensions and by the formula of Teichholz et al., ${ }^{2}$ and as might be expected we found that there was excellent correlation between these methods in our young healthy subjects $(r=0.98, p<0.001)$. There was also good correlation $(p<0.001)$ between the

Table Mean values for diastolic (Dd) and systolic ( $D s)$ minor axis dimensions, fractional shortening ( $F S$ ), peak rates of change of ventricular dimensions ( $d D / d t$ max $)$, heart rate $(H R)$, mean blood pressure $(B P)$, cardiac output $\left(\dot{Q}_{S}\right)$, and systemic vascular resistance $\left(R_{S}\right)$

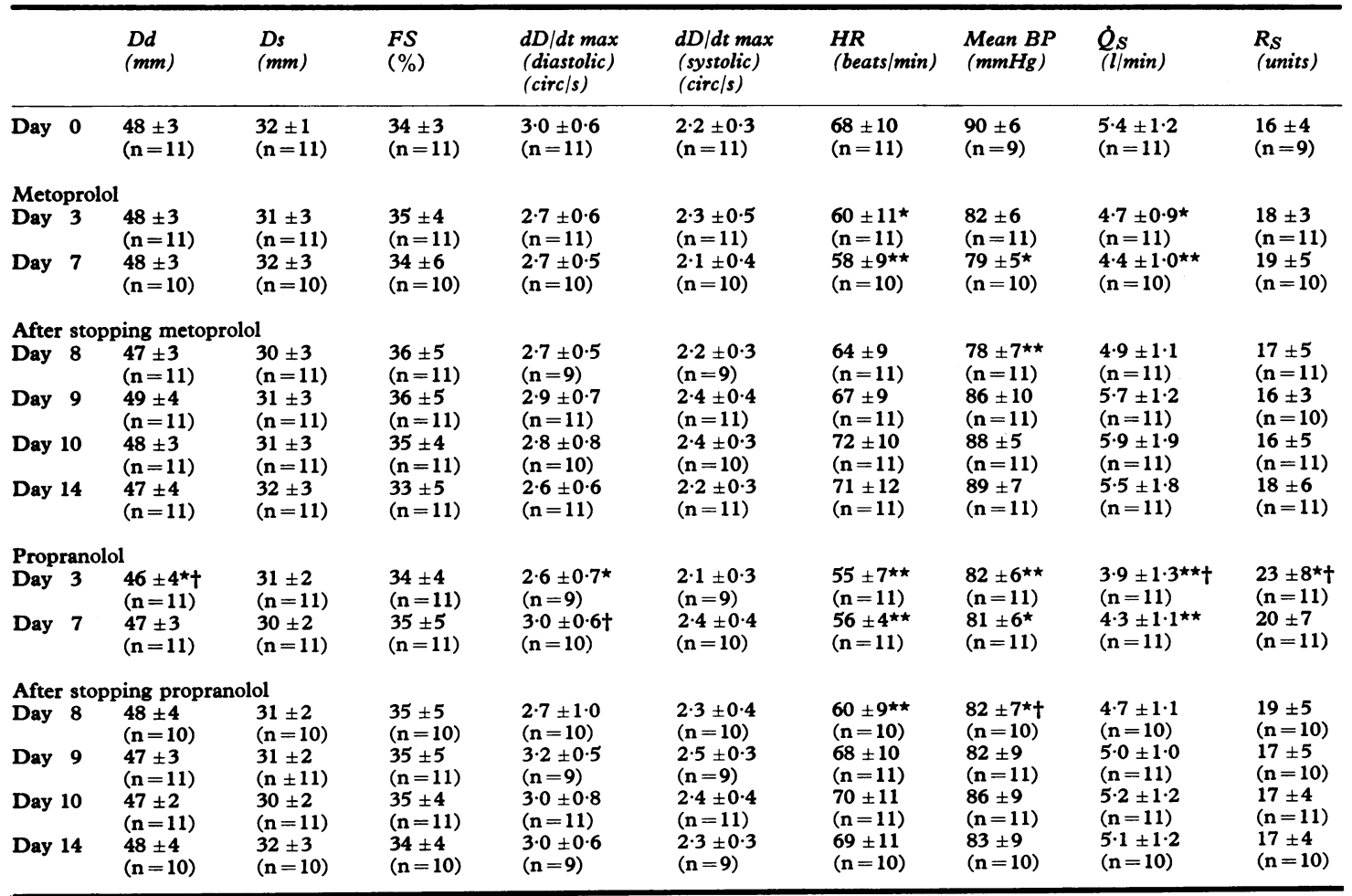

Significant differences (Wilcoxon's signed rank test) from baseline values (day 0 ) are indicated by $\star(p<0.05)$ and $\star \star ~(p<0.01)$. Values during the administration of propranolol which differed significantly from those on the corresponding days on metoprolol are shown thus $t(p<0.05)$. In general, analysis using Student's test gave similar or higher levels of significance, except for increases in peripheral resistance on day 3 of propranolol administration compared with values on day $0(z=2 \cdot 19 \star ; t=2 \cdot 27)$. 
different indices of contractility (FS vs $\mathrm{dD} / \mathrm{dt}_{\max }$, $\mathrm{r}=0.75$; mean $\mathrm{Vcf}$ vs $\mathrm{dD} / \mathrm{dt}_{\max }, \mathrm{r}=0.85$; FS vs mean Vcf, $r=0.84$ ) suggesting that they are all of value in describing left ventricular systolic function.

Our normal values for systolic and diastolic $\mathrm{dD} /$ $\mathrm{dt}_{\max }$ were similar to those reported by Gibson and Brown, ${ }^{15}$ and Paoloni et al. ${ }^{16}$ and were not affected materially by smoothing and averaging during computer analysis. We compared recordings made at $50 \mathrm{~mm} / \mathrm{s}$ and at $100 \mathrm{~mm} / \mathrm{s}$ using as a model two sine waves with a $90^{\circ}$ phase difference, and found no significant differences in the derived "dimensions" and rates of change of "wall motion". We were concerned about differences from cycle to cycle and from day to day, and particularly about the fairly large variations in peak rates of change of dimension noted by Bass and Whitlock. ${ }^{17}$ In other studies we have analysed up to 50 successive cycles in normal subjects with sinus arrhythmia, and found that dimensions varied by as much as 10 per cent and peak rates of change by up to 25 per cent. For this reason we measured at least five cycles and used only recordings of high quality for calculating rates of change of dimension.

It seems to us that this difficulty in obtaining representative measurements of ventricular dimensions and wall motion must apply also to angiocardiographic techniques. There is no information on the beat-to-beat variation which may occur in radiological studies. Echocardiography had the great advantage of allowing us to obtain a much larger sample on any one occasion and to obtain repeated measurements under comparable conditions. Fig. 3 illustrates the variation in ventricular dimensions and in derived stroke volume and "instantaneous" cardiac output in 92 consecutive cycles in one of our subjects.

Although other authors have suggested that the does of metoprolol and propranolol we chose are comparable in effect, ${ }^{18-20}$ we found that there was a

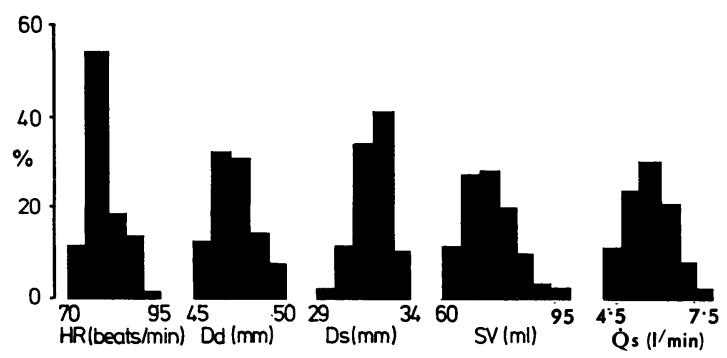

Fig. 3 Frequency plots of heart rate, left ventricular dimensions (Dd, Ds), stroke volume (SV), and "instantaneous" cardiac output ( $\dot{Q}_{s}$ ) in 92 successive cardiac cycles in one normal subject.

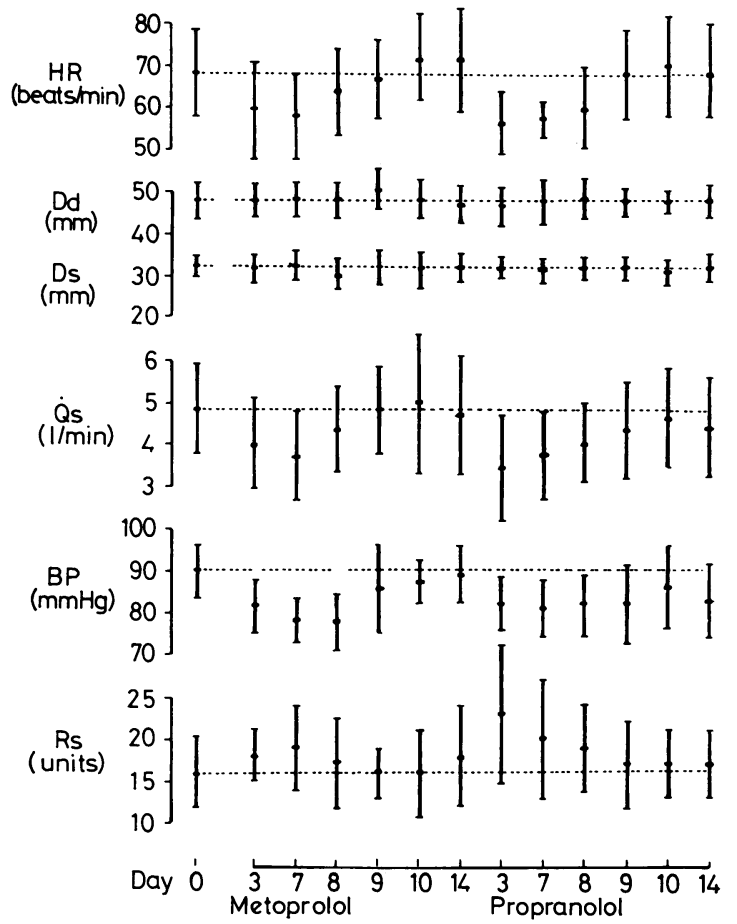

Fig. 4 Heart rate (HR), ventricular dimensions ( $D d$ and $D s)$, cardiac output $\left(\dot{Q}_{S}\right)$, mean blood pressure (BP), and systemic resistance $\left(R_{S}\right)$ during metoprolol and propranolol treatment (days 3,7$)$, and after stopping each drug (days $8,9,10,14$ ). The data have been plotted as if all the metoprolol studies were done first. The dotted lines represent mean values for control measurements.

tendency for propranolol to produce greater falls in heart rate and cardiac output, and significant increases in the systemic vascular resistance. There is a fairly large scatter in the values for cardiac output and systemic resistance which could have been reduced if these had been "corrected" for body surface area, but as the subjects were compared with themselves the levels of significance would not have been altered. Fig. 4 shows the changes observed.

Van Herwaarden et al. ${ }^{20}$ studied subjects after four weeks on metoprolol or propranolol and were able to show that the infusion of adrenaline increased forearm vascular resistance during propranolol treatment, but not during metoprolol treatment; this was found also in acute studies by Johnsson. ${ }^{21}$ This seems to indicate an important difference in the properties of the two drugs which may have clinical relevance.

Crawford et al. ${ }^{8}$ showed that propranolol reduced left ventricular ejection fraction and mean Vcf as 
well as heart rate and blood pressure, and that these effects could be reversed with atropine and phenylephrine. We were not able to show that either drug produced any significant change in indices of left ventricular systolic function (fractional shortening, peak Vcf, or systolic $\mathrm{dD} / \mathrm{dt}_{\max }$ ), though the negative correlation between these indices and systemic vascular resistance suggests either that they are responsive to changes in afterload or that (like heart rate) they are directly affected by beta-adrenergic blocking agents. In any case the net effect is reduction in blood pressure resulting from a fall in cardiac output which is itself largely rate dependent.

Although it would be difficult to show that metoprolol should be preferred to propranolol in clinical practice, except for patients with asthma, the different effects of these and other betaadrenergic blocking agents on peripheral vascular resistance at rest or during exercise or the infusion of catecholamines deserve further investigation. Despite its limitations $M$-mode echocardiography is a most attractive tool for studies of this kind.

We are grateful to Dr P Stanley, Queen Elizabeth Hospital, Adelaide, whose laboratory performed the assays of metoprolol and propranolol, and to Astra Pharmacuticals Pty Ltd and ICI Australia Ltd for supplies of active and matching placebo tablets.

\section{References}

1Degen PH, Reiss W. Simplified method for the determination of oxprenolol and other beta-receptor blocking agents in biological fluid by gas liquid chromatography. $f$ Chromatogr 1976; 121 : 72-5.

${ }^{2}$ Teichholz LE, Kreulen T, Herman MV, Gorlin R. Problems in echocardiographic volume determinations: echocardiographic-angiographic correlations in the presence or absence of asynergy. Am $\mathcal{F}$ Cardiol 1976; 37: 7-11.

${ }^{3} \mathrm{McD}$ conald IG, Feigenbaum H, Chang S. Analysis of left ventricular wall motion by reflected ultrasound. Circulation 1972; 46: 14-25.

${ }^{4}$ Popp RL. Echocardiographic assessment of cardiac disease. Circulation 1976; 54: 538-52.

${ }^{5}$ Popp RL. Current concepts in cardiology: echocardiographic evaluation of left ventricular function. $N \mathrm{Engl}$ f Med 1977; 296: 856-8.

${ }^{6}$ DeMaria AN, Neumann A, Lee G, Fowler W, Mason DT. Alterations in ventricular mass and performance induced by exercise training in man evaluated by echocardiography. Circulation 1978; 57: 237-43.

'Gorwit J, Crawford M, Karliner J, O'Rourke R. Echocardiographic assessment of left ventricular performance in normal subjects receiving oral quinidine (abstract). Circulation 1975; 51 \& 52, suppl II: 191.

${ }^{8}$ Crawford MH, O'Rourke RA, Garza G, Karliner JS. Oral propranolol: effects on left ventricular function in normal subjects (abstract). Circulation 1975; 51 \& 52, suppl II : 172.

${ }^{9}$ Crawford MH, Karliner JS, O'Rourke RA. Favorable effects of oral maintenance digoxin therapy on left ventricular performance in normal subjects: echocardiographic study. Am f Cardiol 1976; 38: 843-7.

${ }^{10}$ Fortuin NJ, Hood WP, Sherman ME, Craige E. Determination of left ventricular volumes by ultrasound. Circulation 1971; 44: 575-84.

${ }^{11}$ Pombo JF, Troy BL, Russell RO. Left ventricular volumes and ejection fraction by echocardiography. Circulation 1971 ; 43: 480-90.

${ }^{12}$ Murray JA, Johnston W, Reid JM. Echocardiographic determination of left ventricular dimensions, volumes and performance. Am $\mathcal{f}$ Cardiol 1972; 30: 252-7.

${ }^{13}$ Cooper RH, O'Rourke RA, Karliner JA, Peterson KL, Leopold GR. Comparison of ultrasound and cineangiographic measurements of the mean rate of circumferential fiber shortening in man. Circulation 1972; 46: 914-23.

${ }^{14}$ Quinones MA, Gaasch WA, Alexander JK. Echocardiographic assessment of left ventricular function. Circulation 1974; 50: 42-51.

${ }^{15}$ Gibson DG, Brown DJ. Measurement of peak rates of left ventricular wall movement in man. Comparison of echocardiography with angiocardiography. $\mathrm{Br}$ Heart f 1975; 37: 677-83.

16Paoloni HJ, Dadd MJ, Wilcken DEL. Measurement of peak rates of left ventricular wall movement by echocardiography (abstract). Aust NZ f Med 1977;7: 558.

17Bass NM, Whitlock RML. Repeatability of left ventricular echocardiograms (abstract). Aust $N Z \mathcal{F}$ Med 1977; 7: 558.

${ }^{18}$ Johnsson G, Nyberg G, Sölvell L. Influence of metoprolol and propranolol on haemodynamic effects induced by physical work and isoprenaline. Acta Pharmacol Toxicol (Kbh) 1975; 36, suppl 5: 69-75.

${ }^{19}$ Bengtsson C. Comparison between metoprolol and propranolol as antihypertensive agents. Acta Med Scand 1976; 199: 71-4.

${ }^{20}$ Van Herwaarden CLA, Fennis JFM, Binkhorst RA, van't Laar A. Haemodynamic effects of adrenaline during treatment of hypertensive patients with propranolol and metoprolol. Eur f Clin Pharmacol 1977 12: 397-402.

${ }^{21}$ Johnsson G. Influence of metoprolol and propranolol on hemodynamic effects induced by adrenaline and physical work. Acta Pharmacol Toxicol (Kbh) 1975; Suppl 5: 59-68.

Requests for reprints to Dr J H N Bett, Royal Brisbane Hospital, Herston Road, Brisbane, Queensland 4029, Australia. 